\title{
ОСОБЕННОСТИ ПОЛИТИКИ ЗАНЯТОСТИ И БЕЗРАБОТИЦЫ В РАЗВИТЫХ СТРАНАХ
}

Куразова Д.А., Албастов А.P., Дудаев T-A.M.

Чеченский государственный университет, г. Грозный, Россия

В данной статье обобщены теоретические положения по регулированию рынка труда и усовершенствован теоретико-методический подход $к$ его исследованию на основе группировка факторов влияния, выделение методов, иелей и инструментов регулирования рынка труда.

Ключевые слова: рынок труда, занятость, безработица, центр занятости населения, регулирование рынка труда, развитые страны.

Усиление конкуренции, развитие экономики знаний, информационных технологий, изменения в содержании и формах труда требуют обновления системы регулирования рынка труда. Для современной России актуальными являются внутренние факторы социально-экономической нестабильности, связанные с усилением социальной напряженности в обществе на фоне снижения уровня жизни, ухудшением условий занятости, территориальными и профессионально-квалификационными диспропорциями между спросом и предложением на рынке труда, обострением ситуации на локальных рынках труда. То есть общественный запрос на эффективные решения в сфере регулирования вопросов занятости является высоким, поскольку ожидания население по повышению благосостояния и качества жизни связаны с реализацией права на достойный труд.

Среди инструментов регулирования рынка труда наиболее перспективными являются те, что учитывают объективное влияние глобальных трендов и направленные на активизацию инновационной занятости, предпринимательской активности населения, обеспечение сбалансированности рынка образовательных услуг и рынка труда, прогнозирование объема и структуры спроса и предложения на рынке труда, повышение конкурентоспособности специалистов и расширение круга достойных рабочих мест. Регулирование рынка труда является важным направлением развития национальной экономики и является объективно необходимым процессом, поскольку он непосредственно влияет на расширение занятости, повышение благосостояния и качества жизни население [1].

В современных условиях основными факторами, влияющими на процессы, которые происходят на рынке труда, являются: структурная перестройка экономики, в частности преобладающее развитие отраслей сферы услуг; ускоренное экономическое рост; наращивание потенциала 
предпринимательства; научно-технический прогресс, информатизация общества; государственное регулирование развития трудового потенциала, рынка труда и занятости. Среди инструментов регулирования рынка труда наиболее перспективными есть те, что направлены на обеспечение сбалансированности рынка образовательных услуг и рынка труда в условиях трансформации структуры занятости; прогнозирование и планирование развития рынка труда; улучшение профессионально-квалификационной подготовки кадров в соответствии с требованиями рынка труда и научнотехнического прогресса; повышение мотивации к труду, занятости и предпринимательства.

В основу работ А. Смита (1723-1790) были положены утверждение о свободной конкуренции как условии оптимального использования материальных, финансовых и человеческих ресурсов. А. Смит утверждал, что уровень занятости населения обусловлен размером средней ставки заработной платы одного работника. Английский экономист Д. Риккардо (1772-1823) обосновал зависимость размеров заработной платы в предложения выражается в том, что с увеличением зарплаты выше минимального уровня, необходимого для воспроизводства населения, растет предложение труда, что влияет на снижение зарплаты. В конце XIX в. сформировались различные школы и направления в исследовании рынке труда. Здесь можно выделить ряд основных концептуальных подходов к анализу рынка труда: марксистский, неоклассический, в том числе монетаристский, кейнсианский, неокейнсианский, институциональный [3].

Для решения проблемы малой популяризации центров занятости населения необходимо организовать плотное взаимодействие с Интернетплощадками по содействию поиска работы. Данная мера позволит повысить популярность центров занятости населения, а также даст возможность вести более качественный мониторинг списка актуальных вакансий, с последующей его обработкой, что поможет отслеживать и выявлять не добросовестных работодателей, а также позволит расширить базу актуальных вакансий на территории населенных пунктов. Кроме того, для роста популяризации Центра, необходимо организовать плотной взаимодействие с аудиторией в социальных сетях и мессенджерах.

Для решения проблемы подбора вакансий в соответствии с полученным образованием среди безработных необходимо проводить анкетирование, социальное и психологическое поддержание учеников 9-х и 11-х классов в выборе профессий и специальностей, проводить возможные экскурсии на предприятиях и в учреждениях. Показывать небольшие видеофильмы о профессиях, которые могут использоваться в профориентационной работе с молодежью. Для решения проблемы низкой конкурентоспособности отдельных категорий граждан, к которым относятся: молодежь, женщины и инвалиды, необходимо комплексное взаимодействие по всем направлениям категорий. Так, для решения проблемы трудоустройства молодежи нужно молодежи в выборе профессии, а также информировать ее о состоянии рынка труда на 
основе проведенных анализов. Кроме того, рассматривать стратегию развития кадров в будущем. Также необходимо содействовать созданию мест для практик и стажировок на предприятиях и в организациях [2].

Обычно процедура отбора персонала проходит в несколько этапов:

1. Подготовка документов для проведения конкурса (содержит всю информацию, документы, регламентирующие процесс, описание должности, членов конкурсной комиссии, примерные вопросы интервью и др.).

2. Формирование конкурсной комиссии (включая подготовку членов по всем вопросам конкурса, выбор председателя отборочной комиссии).

3. Установка критериев отбора (знания, навыки, установки кандидатов на должность) [3].

Эксперты из Великобритании отмечают, что уже на этапе подготовки к проведению конкурса можно значительно облегчить работу комиссии и организаторов в дальнейшем. При правильной формулировке объявления об открытии вакансии уже начинается отбор кандидатов, так как различные люди обращают свое внимание на определенные аспекты места работы, должности и требований.

Таким образом, явка необходимых кандидатов может быть обеспечена уже при подготовке первых 3-4 этапов конкурса. В контексте данного исследования представляют интерес этапы проведения непосредственно конкурса на замещение должности, а также проверка рекомендаций (этапы 5 и 6). Наиболее достоверными при отборе кадров являются методы моделирования работы («job simulation»), которые включают защиту презентации, выполнение заданий, тестов с использованием компьютера и так далее). Подобные методы позволяют предположить, как работник будет выполнять должностные обязанности в будущем. Также эффективным считается метод систематического анализа биографических данных кандидатов («Biodata»). Предоставленные кандидатом или собранные сотрудниками данные систематизируются и на их основе производятся выводы: может ли кандидат занимать данную должность [1].

Стоит отметить, что в зарубежной практике редко встречается понятие «конкурсной процедуры». Чаще всего используется термин «interview», который включает не только привычное в России «интервью» - ответы на соответствующие вопросы, но также и решение кейсов, анализ документов и так далее. Таким образом, методы, применяемые в Северо-Западных территориях Канады при отборе кадров в местные органы власти, сводятся к вопросам конкурсной комиссии (в форме теста и собеседования), основанным на рабочих ситуациях. Однако существует множество нюансов в проведении интервью, которые также учитываются при подготовке и в процессе проведения конкурса. Считается, что лучшим основанием для формулирования вопросов является описание работы и должности, на которую претендует конкурсант.

Внедрение и реализация предложенных направлений государственного регулирование рынка труда, направленных на решение указанных проблем, 
является важным инструментом, способствующим обеспечению производительности занятости, а именно: повышению конкурентоспособности, как работников, так и экономики; совершенствованию государственного стратегического социально-экономического планирования; созданию благоприятных условий и стимулов для возвращения трудящихся-мигрантов в Россию; повышению социальных стандартов, уровня оплаты труда, мотивации труда, уровня охраны здоровья, эффективности и оперативности деятельности центров занятости и т.п.

\section{Исследование выполнено при финансовой поддержке РФФИ в рамках научного проекта № 19-310-90035/19.}

\section{Список литературы}

1. Wills J., Datta K., Evans Y., Herbert J., McIlwaine C. Global Cities at work: New Division of labour. - London: Pluto, 2010. - 256 p.

2. Fleetwood S. Sketching a socio-economic model of labour markets // Cambridge Journal of Economies. 2011. Vol. 35. № 1. p. 15-38.

3. Белохвостова Н.В. Механизмы государственного регулирования занятости населения // Сервис в России и за рубежом. 2016. Т. 10. № 6 (67). - С. 90-100. 